\title{
Effect of Endobronchial Coils on Exercise Tolerance and Lung Functions in Patients with Severe Emphysema - A Retrospective Cohort Study of 48 Patients
}

\author{
Barak Pertzov (iD) ${ }^{1,2}$ \\ Maysaa Soliman ${ }^{2}$ \\ Yael Shostak ${ }^{1,2}$ \\ Moshe Heching ${ }^{1,2}$ \\ Dror Rosengarten ${ }^{1,2}$ \\ Gabriel Izbicki iD ${ }^{3,4, *}$ \\ Mordechai Reuven Kramer ${ }^{1,2, *}$ \\ 'Pulmonary Division, Rabin Medical \\ Center, Petach Tikva, Israel; ${ }^{2}$ Sackler \\ Faculty of Medicine, Tel Aviv University, \\ Tel Aviv, Israel; ${ }^{3}$ Pulmonary Institute, \\ Shaare Zedek Medical Center, Jerusalem, \\ Israel; ${ }^{4}$ Hebrew University-Hadassah \\ Medical School, Jerusalem, Israel
}

*These authors contributed equally to this work
Correspondence: Barak Pertzov

Pulmonary Division, Rabin Medical

Center, Petach Tikva, Israel

Tel $+972-3-9377221 / 3$

Fax +972-3-924209।

Email pertzovb@gmail.com
Background: Lung volume reduction with endobronchial coils treatment (ECT), for patients with severe emphysema, has shown modest improvement in exercise capacity and lung functions in clinical trials, yet the benefit of this procedure is still unclear.

Methods: We conducted a multicenter retrospective cohort study including all patients who underwent ECT in Israel and a propensity score matched control group of patients with chronic obstructive pulmonary disease (COPD) that were treated with usual care. The primary outcome was six-minute walk test distance (6MWTD), secondary outcomes were lung function tests and patient survival.

Results: Overall, 46 patients were included in the ECT group. Their mean 6MWTD at

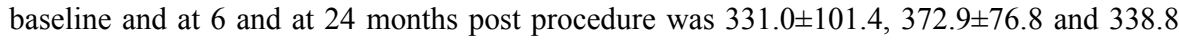
\pm 104.8 , respectively (overall $\mathrm{P}=0.04$, pairwise comparison: baseline to 6 months $(\mathrm{P}=0.1)$, baseline to 24 months $(\mathrm{P}=1.0))$. Mean FEV1 values at baseline and at 6 and at 24 months post procedure were $0.86 \pm 0.38,0.92 \pm 0.37$ and $0.82 \pm 0.36$ liters, respectively (overall $\mathrm{P}=0.003$, pairwise comparison: baseline to 6 months $(\mathrm{P}=0.04)$, baseline to 24 months $(\mathrm{P}=0.75))$. The median 6MWTD for the ECT and control groups at 24 months were 333.0 (262.5-390) and $280(210-405)$, respectively $(\mathrm{P}=0.16)$. There was no difference in overall survival $(\mathrm{P}=0.84)$. Heterogenous emphysema was a significant predictor of treatment success in univariate analysis $(\mathrm{p}=0.004)$.

Conclusion: Lung volume reduction with endobronchial coils may improve the exercise capacity and FEV1 of COPD patients. However, the majority of the effect was diminished after 24 months. The current state of evidence does not support regulatory approval of ECT and warrant its use only after consideration of the benefit-harm ratio in a highly selected patient population.

Keywords: emphysema, endobronchial coils, lung volume reduction, six-minute walk, residual volume, FEV1, survival

\section{Introduction}

Endoscopic lung volume reduction (ELVR) with endobronchial nitinol coils is a viable treatment option for patients with advanced chronic obstructive pulmonary disease (COPD). ${ }^{1}$ The RESET trial, published in 2013, was the first randomized controlled trial (RCT) to evaluate the benefit of endobronchial coils treatment (ECT). The study included 23 patients in the ECT groups and 24 patients in the control group and reported a significant improvement in St George's Respiratory 
Questionnaire (SGRQ), 90 days after the last coils treatment. ${ }^{2}$ Another RCT, with a similar sample size, by Zoumot et al reported a significant improvement in SGRQ, FEV1 and six-minute walk test distance (6MWTD) one year after ECT. ${ }^{3}$ The REVOLENS trial which included 100 patients, 50 patients in each treatment group, reported a modest improvement in 6MWTD, lung functions and SGRQ at 6 and 12 months. ${ }^{4}$ The RENEW trial, which is currently, the largest RCT conducted to evaluate ECT, included 315 patients, 158 in the ECT group and 157 in the usual care group. The results showed a statistically significant improvement in 6MWTD at 12 months. Yet, this change was modest and with questionable clinical significance. Moreover, the rate of adverse events was higher in the ECT group. ${ }^{5}$ The benefit of ECT was also reported in two retrospective trials that showed an improvement in arterial blood gas and a decrease in anxiety and depression symptoms. ${ }^{6,7}$ To improve clinical outcomes, a post hoc analyses of the RENEW trial was conducted to identify baseline predictors of procedure success. The analysis showed that significant hyperinflation and quantitative CT scan analysis are important for patient selection. ${ }^{8,9}$ To prospectively validate these results, the ELEVATE study was designed to include patients with significant hyperinflation (residual volume $(\mathrm{RV})>200 \%$ ). The trial, that was stopped prematurely by the sponsor, included 120 patients, 80 in the ECT group and 40 in the usual care group, reported a clinically significant improvement in lung function and quality of life at six months. Nevertheless, with a higher probability of serious adverse events. ${ }^{10}$ Since clinical trials published to date, reported a modest improvement in lung functions with a higher risk of adverse events and long-term data is sparse, the benefit of ECT is yet undetermined. In this trial, we present the Israeli long-term experience with ECT in an effort to contribute to the growing body of evidence regarding the benefit of this procedure.

\section{Methods}

We conducted a multicenter retrospective cohort study, inclusion criteria were all patients who underwent unilateral or bilateral endoscopic lung volume reduction procedure with endobronchial coils at Rabin and Shaare Zedek Medical Centers in Israel (RMC and SZMC), there were no exclusion criteria. We have also included a propensity score matched control group of 49 COPD patients from Rabin Medical Center ambulatory clinic. The inclusion criteria for the control group were diagnosis of COPD and data regarding pulmonary function tests. The exclusion criteria were thoracic surgical procedure (eg, lung volume reduction surgery, wedge resection, lobectomy or pneumonectomy) or endoscopic treatment for lung volume reduction. The control group was matched for age, gender, baseline FEV1 and 6MWT distance. The primary outcome was 6-minute walk test distance at 24 months post procedure in comparison to the distance at baseline and at 6 months. Secondary outcomes were change from baseline in FEV1, carbon monoxide diffusing capacity (DLCO) and residual volume (RV) within the ECT group and the change in FEV1, RV, 6MWT distance and survival in comparison to the control group. The 6MWD at baseline was calculated as the mean of the last two tests before the first procedure. The distance at 6 months was calculated as the mean of all values registered between 1 and 6 months follow-up. The value at 24 months was calculated as the mean of all values registered between 18 and 30 months. FEV1, RV and DLCO were collected as described for the primary outcome. Pulmonary function tests were measured with the Pulmonary function testing system ZAN 300 nSpire health. Lung volumes including total lung capacity (TLC) and residual volume were measured with a Pressure (Closed-Type) Plethysmograph. Diffusion capacity was measured using the single breath methods with $0.3 \%$ carbon monoxide. Survival was analyzed as time to death or lung transplant. A post hoc analysis for predictors of procedure success was added after data analysis. Treatment success was defined by two objective parameters in the 6MWT, first the 6MWTD had to improve after the procedure by 30 meters or more and second the 6MWTD at 24 months had to be longer than the baseline value. Both parameters had to be fulfilled for the procedure to be considered successful. The study was approved by the RMC institutional ethical review board (IRB number: 0785-16-RMC).

\section{Statistical Methods}

Dispersion variables were presented as average with standard deviation (SD) or median and interquartile range (IQR) as appropriate. The demographic and baseline variables were compared with the chi-square test, or the Mann-Whitney $U$-test, as appropriate. The primary outcome was analysed with general linear model and results were reported in estimated marginal means. Pairwise comparison was adjusted for multiple comparisons (Bonferroni). Only patients with data in all time points were included in the repeated measures analysis. The 
control group was matched to the intervention group by propensity score matching with a caliper of 0.2 for age, gender, baseline FEV1 and baseline 6MWT distance. Comparison of outcomes between the intervention and control groups was analysed with the chi-square test and the Mann-Whitney $U$-test. Survival analysis was analysed with the Kaplan-Meier curve and the Log rank test. A P-value of 0.05 was considered as significant. Statistical analysis was conducted with the SPSS version 27 software.

\section{Procedure Flow}

All procedures were completed in the bronchoscopy suite under moderate sedation using midazolam (1 mg), fentanyl (50-100 $\mathrm{mcg}$ ) and propofol (dosing according to procedure length). First, the treated lobe and subsegments were identified. The bronchoscope was placed at the ostium of the treated subsegment. A catheter was inserted to measure the distance from the pleura in order to determine the appropriate coil length (100, 150 or $200 \mathrm{~mm})$. The coil was loaded to the loading system and then deployed under fluoroscopic guidance into the desired lung segment. Between 8 and 12 coils were deployed into each lobe. At first, patients were hospitalized after the procedure for observation. However, due to the low complication rate, the procedure protocol was changed, and patients were discharged on the same day, if the chest $x$-ray was with no sign of pneumothorax and the patient was feeling well.

\section{Results}

Overall, 39 patients from Rabin Medical Center and 7 patients from Shaare Zedek medical center were included. This cohort includes all endobronchial coils procedures performed in Israel. Thirty patients underwent bilateral coils placement, and 16 patients underwent unilateral coils placement (Table S1).

The mean age (SD) of the cohort was 64.1 (6.9), 29 patients were males (63.0\%). The majority of patients were in GOLD stage 3 and $4(95.6 \%)$ and the median (IQR) BODE score (BMI, obstruction, dyspnea, and exercise capacity) were 6 (5-7) (Table 1). Mean 6MWTD at baseline and at 6 and 24 months post procedure was 331.0 $\pm 101.4,372.9 \pm 76.8$ and $338.8 \pm 104.8$, respectively (overall $\mathrm{P}$ value $=0.04)$, Pairwise comparison of baseline to 6 and baseline to 24 months yielded $\mathrm{P}$ values of 0.1 and 1.0, respectively. Mean FEV1 values at baseline and at 6 and 24 months post procedure were $0.86 \pm 0.38,0.92 \pm 0.37$ and $0.82 \pm 0.36$ liters $(\mathrm{L})$, respectively $(\mathrm{P}=0.003)$. Pairwise
Table I Baseline Clinical and Demographic Characteristics

\begin{tabular}{|c|c|c|c|c|c|}
\hline \multirow{2}{*}{\multicolumn{2}{|c|}{$\begin{array}{l}\text { Medical } \\
\text { Center }\end{array}$}} & \multicolumn{2}{|c|}{ Coils Treatment } & \multirow{2}{*}{$\begin{array}{l}\text { Control } \\
\text { RMC }\end{array}$} & \multirow[t]{3}{*}{$P$ value } \\
\hline & & RMC & SZMC & & \\
\hline \multicolumn{2}{|l|}{$\begin{array}{l}\text { Number of } \\
\text { Patients }\end{array}$} & 39 & 7 & 49 & \\
\hline \multicolumn{2}{|c|}{ Age (mean $\pm S D)$} & \multicolumn{2}{|c|}{$64.1 \pm 6.9$} & $65.0 \pm 10.3$ & 0.62 \\
\hline \multicolumn{2}{|c|}{ Male gender (\%) } & \multicolumn{2}{|c|}{$29(63.0)$} & $31(63.3)$ & 0.98 \\
\hline \multicolumn{2}{|c|}{$\begin{array}{l}\text { Baseline FEVI \% } \\
\text { pred }^{\text {a }}\end{array}$} & \multicolumn{2}{|c|}{$29.0(23.0-38.2)$} & $\begin{array}{l}31.0(21.5- \\
42.0)\end{array}$ & 0.56 \\
\hline \multicolumn{2}{|c|}{$\begin{array}{l}\text { Baseline DLCO } \\
\text { \%pred }^{\text {a }}\end{array}$} & \multicolumn{2}{|c|}{$39.0(30.0-44.75)$} & $\begin{array}{l}39.0(29.0- \\
49.0)\end{array}$ & 0.58 \\
\hline \multicolumn{2}{|c|}{$\begin{array}{l}\text { Baseline TLC \% } \\
\text { pred }^{\text {a }}\end{array}$} & \multicolumn{2}{|c|}{$127(|22-| 4 \mid)$} & $\begin{array}{l}\text { III.5 (I05.75- } \\
126.75)\end{array}$ & 0.01 \\
\hline \multicolumn{2}{|l|}{$\begin{array}{l}\text { Residual } \\
\text { volume } \mathrm{mL}^{\mathrm{a}}\end{array}$} & \multicolumn{2}{|c|}{$5.42(4.32-5.96)$} & $\begin{array}{l}3.97(3.22- \\
5.01)\end{array}$ & 0.001 \\
\hline GOLD stage & $\begin{array}{l}4 \\
3 \\
2 \\
1\end{array}$ & $\begin{array}{l}23 \\
20 \\
2 \\
0\end{array}$ & & $\begin{array}{l}18 \\
24 \\
5 \\
0\end{array}$ & 0.21 \\
\hline \multicolumn{2}{|c|}{ BODE score ${ }^{a}$} & \multicolumn{2}{|c|}{$6(5-7)$} & $5(4-7)$ & 0.11 \\
\hline \multicolumn{2}{|l|}{$\begin{array}{l}\text { Supplemental } \\
\text { oxygen (\%) }\end{array}$} & \multicolumn{2}{|c|}{$8(17.4)$} & $6(12.8)$ & 0.53 \\
\hline \multicolumn{2}{|l|}{ Pack years ${ }^{a}$} & \multicolumn{2}{|c|}{$50(40-75)$} & $50(40-70)$ & 0.80 \\
\hline \multicolumn{2}{|l|}{ DM (\%) } & \multicolumn{2}{|c|}{$7(15.6)$} & $14(29.8)$ & 0.10 \\
\hline \multicolumn{2}{|l|}{ HTN (\%) } & \multicolumn{2}{|c|}{$17(37.8)$} & $13(27.7)$ & 0.30 \\
\hline \multicolumn{2}{|l|}{ IHD (\%) } & \multicolumn{2}{|c|}{$10(22.7)$} & $8(17.0)$ & 0.49 \\
\hline
\end{tabular}

Note: ${ }^{\mathrm{D} D a t a}$ presented in median and IQR.

Abbreviations: RMC, Rabin Medical Center; SZMC, Shaare Zedek Medical Center; FEVI \%pred, forced expiratory volume in the first second percent predicted; DLCO \%pred, carbon monoxide diffusing capacity percent predicted; Baseline TLC \%pred, total lung capacity percent predicted; BODE score, BMI, obstruction, dyspnea, and exercise capacity; DM, diabetes mellitus; HTN, hypertension; IHD, ischemic heart disease; IQR, interquartile range.

comparison between FEV1 values at baseline to values at 6 and 24 months yielded P values of 0.04 and 0.75 , respectively. Mean RV values at baseline, 6 and 24 months were $5.28 \pm 1.59,4.91 \pm 1.43$ and $5.07 \pm 1.30 \mathrm{~L}$, respectively $(\mathrm{P}=0.45)$. Pairwise comparison between RV values at baseline to values at 6 and 24 months yielded $P$ values of 0.6 and 1.0, respectively (Table 2 and Figure 1). Overall complication rate was low. Out of 76 procedures (30 bilateral and 16 unilateral), four patients suffered from post procedural pneumothorax and three from post procedural hemoptysis. During the post procedural follow-up period, three patients were hospitalized due to pneumonia 
Table 2 Within Group Comparison. Repeated Measures Analysis Showing Estimated Marginal Means of Six-Minute Walk Test Distance, FEVI and Residual Volume at Baseline, 6 Months and 24 Months in Patients After Lung Volume Reduction with Endobronchial Coils

\begin{tabular}{|l|c|c|c|c|c|c|c|}
\hline $\begin{array}{l}\text { Pulmonary Function } \\
\text { Test }\end{array}$ & N* & Baseline & 6 Months & 24 Months & \multicolumn{3}{|c|}{ P value } \\
\cline { 5 - 8 } & & & & & & & \\
Overall & $\begin{array}{c}\text { Baseline vs 6 } \\
\text { Months }\end{array}$ & Maseline vs 24 \\
MMWTD & & & & & 0.10 & 1.0 \\
FEVI & 23 & $331.0 \pm 101.4$ & $372.9 \pm 76.8$ & $338.8 \pm 104.8$ & 0.04 & 0.04 & 0.75 \\
RV & 32 & $0.86 \pm 0.38$ & $0.92 \pm 0.37$ & $0.82 \pm 0.36$ & 0.003 & 0.60 & 1.0 \\
\hline
\end{tabular}

Note: *The analysis included only patients with data in all time points.

Abbreviations: 6MWTD, six-minute walk test distance; FEVI, forced expiratory volume in the first second; RV, residual volume.

(Table S1). There were no procedural-related deaths. The demographic and baseline clinical characteristics of the intervention and control groups were similar except for a higher baseline RV and TLC for the intervention group (Tables 1 and 3). The median (IQR) 6MWTD at 24 months was $333.0(262.5-390)$ and $280(210-405)$ for the ECT and control groups, respectively $(\mathrm{P}=0.16)$. The median FEV1 at 24 months was $0.77(0.57-0.92)$ and 0.73 (0.56-1.05) for the ECT and control groups, respectively $(\mathrm{P}=0.78)$ and median RV at 24 months was 4.66 (3.89$6.21)$ and $4.22(3.28-5.49)$ for the ECT and control groups, respectively $(\mathrm{P}=0.15)$. Median follow-up time was 42.89 months (IQR 29.9-59.66) for the ECT group and 34.9 (IQR 21.59-56.96) for the control group ( $\mathrm{P}=0.19)$. During this time 9 patients died in the ECT group and 11 in the control group $(\mathrm{P}=0.77)$. Additionally, six patients had undergone lung transplantation in the ECT group and five in the control group ( $\mathrm{P}=0.63$ ) (Table 3). There was no difference in overall survival between groups $(\mathrm{P}=0.84)$ (Figure 2). Treatment success was seen in $25 \%(12 / 46)$ of patients, Heterogenous emphysema was seen in $83.3 \%$ of patients with a successful procedure in comparison to $35.5 \%$ in patients with unsuccessful procedure $(\mathrm{p}=0.004)$ (Table 4).

\section{Discussion}

In this study, we have presented the Israeli experience with endoscopic lung volume reduction using endobronchial coils. The results showed that ECT generate a short-term improvement in lung functions and exercise capacity but does not create a change in the course of the disease. Slight improvement is seen after 6 months which then slowly dwindles until the patient is back to the baseline values at 12 to 24 months. When compared to the control group, the graphs that first diverged at 6 months start to converge and at 24 months both groups are again at a similar clinical state. Nevertheless, if not treated, these patients would most probably have a progression of their emphysema during the 2 observed years, which we could obviously postpone. Survival was similar between groups. These results are in agreement with the RCTs and singlearm studies conducted to evaluate ECT, which showed an improvement in lung functions within 1 year after the procedure..$^{2-5,10-12}$ The results are also in agreement with the two-year follow-up of the REVOLENS study which showed that by 2 years there was no difference in 6MWTD and FEV1 between groups. ${ }^{13}$ In comparison to other methods of endoscopic lung volume reduction, a study that evaluated long-term outcomes with
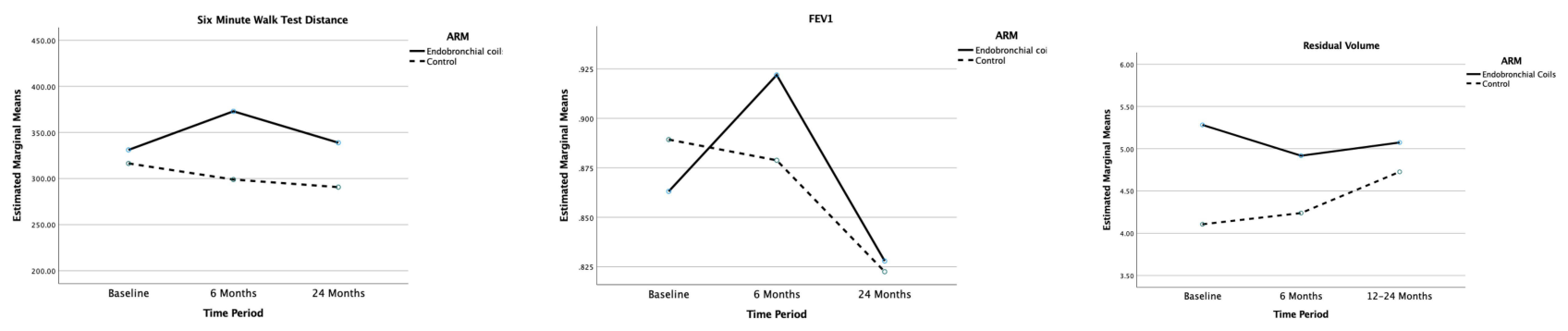

Figure I Six-minute walk test distance (6MWTD), FEVI and residual volume (RV) values for the intervention and control groups at baseline and at 6 and 24 months post procedure (intervention) or since follow-up commencement (control). Values for the control group are presented in Table S2. 
Table 3 Comparison of Six-Minute Walk Test Distance, FEVI, Residual Volume, Lung Transplant Recipients and Mortality Between the Endobronchial Coils and Control Group

\begin{tabular}{|c|c|c|c|c|}
\hline & & Endobronchial Coils N=46 & Control $N=49$ & $\mathbf{P}$ value \\
\hline \multirow[t]{2}{*}{$6 \mathrm{MWTD}^{\mathrm{a}}$} & Baseline & $325.0(196.25-390.0)$ & $342.0(240-405)$ & 0.58 \\
\hline & 24 months & $333.0(262.5-390)$ & $280(210-405)$ & 0.16 \\
\hline \multirow[t]{2}{*}{$\mathrm{FEVI} \mathrm{I}^{\mathrm{a}}$} & Baseline & $0.76(0.61-0.97)$ & $0.82(0.63-1.06)$ & 0.47 \\
\hline & 24 months & $0.77(0.57-0.92)$ & $0.73(0.56-1.05)$ & 0.78 \\
\hline \multirow[t]{2}{*}{$\mathrm{RV}^{\mathrm{a}}$} & Baseline & $5.42(4.32-5.96)$ & $3.97(3.22-5.01)$ & 0.001 \\
\hline & 24 months & $4.66(3.89-6.21)$ & $4.22(3.28-5.49)$ & 0.15 \\
\hline \multirow[t]{2}{*}{$\mathrm{TLC}^{\mathrm{a}}$} & Baseline & $7.83(6.70-8.65)$ & $6.87(5.66-7.46)$ & 0.03 \\
\hline & 24 months & $7.01(6.14-8.36)$ & $6.64(5.28-7.39)$ & 0.10 \\
\hline \multicolumn{2}{|c|}{ Median follow-up time (months) ${ }^{\mathrm{a}}$} & $42.89(29.90-59.66)$ & $34.9(21.59-56.96)$ & 0.19 \\
\hline \multicolumn{2}{|c|}{ Mortality (\%) } & $9(20.0)$ & II (22.4) & 0.77 \\
\hline \multicolumn{2}{|c|}{$\begin{array}{l}\text { Median survival for deceased } \\
\text { patients }^{\mathrm{a}}\end{array}$} & $20.27(8.86-42.90)$ & $18.16(16.09-22.04)$ & 0.87 \\
\hline \multicolumn{2}{|c|}{ Lung transplant (\%) } & $6(13.3)$ & $5(10.2)$ & 0.63 \\
\hline
\end{tabular}

Note: ${ }^{\text {DData }}$ presented as median and IQR.

Abbreviations: 6MWTD, six-minute walk test distance; FEVI, forced expiratory volume in the first second; RV, residual volume; TLC, total lung capacity; IQR, interquartile range.

endobronchial valve therapy reported superior results with a higher proportion of patient maintaining the initial improvement in FEV1, RV and 6MWTD. ${ }^{14}$

The general positive effect seen in the results is not the effect seen at the individual patient level, while some patients had a significant clinical improvement after ECT, others had no clinical improvement or even deterioration. To further evaluate these results, we conducted a post hoc analysis for predictors of procedure success. Only $25 \%$
$(12 / 46)$ of the patients fulfilled the requirements for treatment success. Although the number of outcomes was too small for multivariate analysis, univariate analysis showed that heterogenous emphysema and lack of supplemental oxygen dependence were predictors of procedure success (Table 4). The baseline RV was not different between the success and no success groups however, the baseline RV was quite high in the entire cohort (median 245\%). Similar results were shown in a post hoc analysis of the RENEW

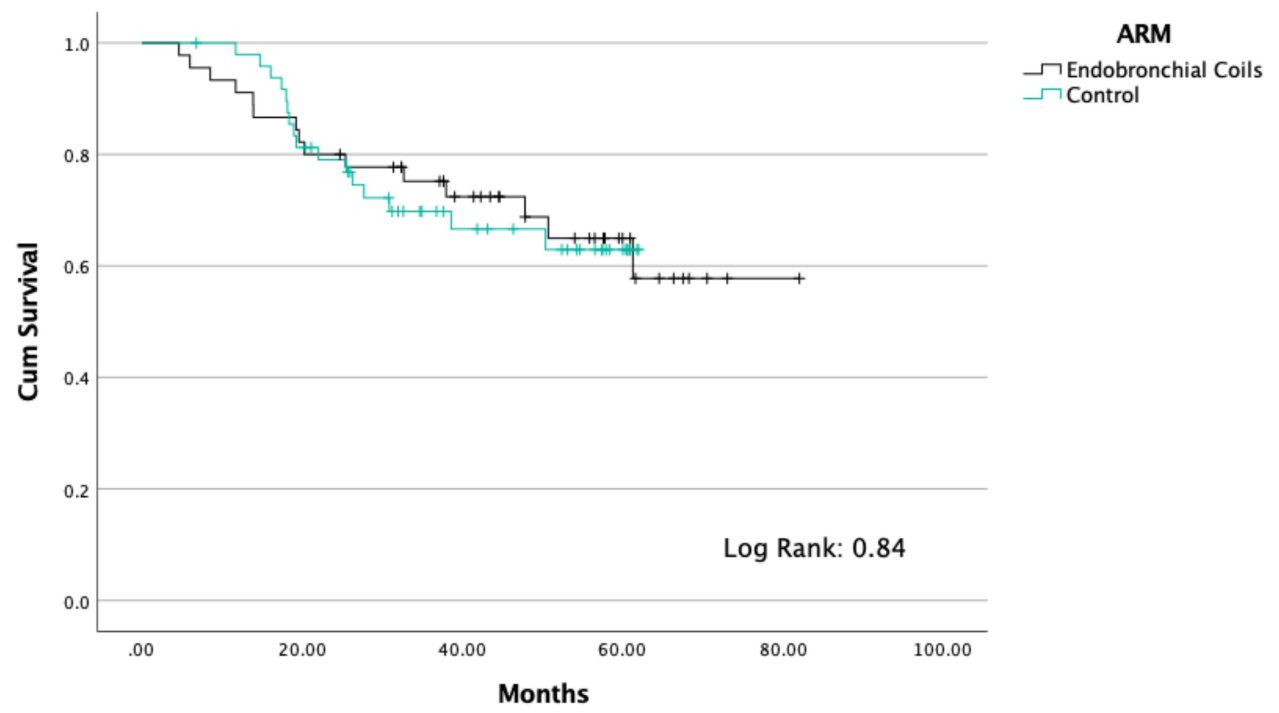

Figure 2 Kaplan-Meier Curve presenting overall survival (death or lung transplant) for the intervention and control groups. Log Rank value is presented at the bottom of the graph. 
Table 4 Post Hoc Analysis for Predictors of Procedure Success

\begin{tabular}{|l|c|c|c|}
\hline \multirow{2}{*}{$\begin{array}{l}\text { Demographicl } \\
\text { Clinical Predictor }\end{array}$} & \multicolumn{2}{|c|}{ Success } & \multirow{2}{*}{ P value } \\
\cline { 2 - 3 } n & $\mathbf{1 2}$ & - & \multirow{2}{*}{$\mathbf{3 4}$} \\
\hline Age & $63.17 \pm 5.49$ & $64.4 \pm 7.48$ & 0.48 \\
\hline Male gender & $9(75.0)$ & $20(58.8)$ & 0.26 \\
\hline $\begin{array}{l}\text { Heterogeneous } \\
\text { emphysema }\end{array}$ & $10(83.3)$ & $12(35.3)$ & 0.004 \\
\hline $\begin{array}{l}\text { Baseline residual volume } \\
\text { (\%predicted) }\end{array}$ & $\begin{array}{c}235.5 \\
(206.5-\end{array}$ & $\begin{array}{c}249.0 \\
(218.25-\end{array}$ & 0.39 \\
\hline $\begin{array}{l}\text { Baseline FEVI (\% } \\
\text { predicted) }\end{array}$ & $\begin{array}{c}359.25) \\
(24.75-\end{array}$ & $\begin{array}{c}26.5(22.75- \\
38.75)\end{array}$ & 0.23 \\
\hline Supplemental oxygen & 0 & $8(23.5)$ & 0.07 \\
\hline
\end{tabular}

Abbreviation: FEVI, forced expiratory volume in the first second.

trial that reported significant hyperinflation (residual volume $\geq 200 \%$ predicted) and Quantitative CT analysis as critical factors for patient selection. ${ }^{9}$

The overall survival was similar between groups. The median BODE score in the intervention group was 6 (IQR $5-7)$ and the 4-year survival was $69.6 \%(32 / 46)$ which is slightly higher than the historical BODE cohort that reported a survival of $57 \%$ at 4 years and in agreement with the extended follow-up of the RESET trial which reported a survival of $64.4 \%$ at 4 years. ${ }^{15,16}$

This study has several limitations, first its retrospective design. Second, lack of quality-of-life evaluation and third, incomplete individual patient data in various time periods which reduced the number of patients included in the repeated measures analysis. The control group was matched according to age, gender, baseline FEV1 and 6MWTD. However, differences were seen in RV and BODE score. These differences are probably because the ECT group was chosen according to parameters for intervention, eg, hyperinflation and severe disease, while the control group was matched from a cohort of ambulatory clinic patients.

In conclusion, lung volume reduction with endobronchial coils may improve the exercise capacity and FEV1 of COPD patients. However, the majority of the effect was diminished after 24 months. The current state of evidence does not support regulatory approval of ECT and warrant its use only after consideration of the benefit-harm ratio in a highly selected patient population.

\section{Data Sharing Statement}

All datasets on which the conclusions of the paper rely are available upon request.

\section{Statement of Ethics}

This study was conducted in accordance with the Declaration of Helsinki. All organs were donated voluntarily with written informed consent, and in accordance with the Declaration of Istanbul.

\section{Acknowledgments}

The authors express their gratitude to Ms. Dalia Dawn Orkin for her English language contributions and editing services. Gabriel Izbicki and Mordechai Reuven Kramer are co-last authors for this study.

\section{Funding}

There is no funding to report.

\section{Disclosure}

The authors have no conflicts of interest to declare.

\section{References}

1. Gold Reports for Personal Use [Internet]. Global initiative for chronic obstructive lung disease - GOLD. [cited March 5, 2020]. Available from: https://goldcopd.org/gold-reports/. Accessed September 30, 2021.

2. Shah PL, Zoumot Z, Singh S, et al. Endobronchial coils for the treatment of severe emphysema with hyperinflation (RESET): a randomised controlled trial. Lancet Respir Med. 2013;1 (3):233-240. doi:10.1016/S2213-2600(13)70047-X

3. Zoumot Z, Kemp SV, Singh S, et al. Endobronchial coils for severe emphysema are effective up to 12 months following treatment: medium term and cross-over results from a randomised controlled trial. PLoS One. 2015;10(4):e0122656. doi:10.1371/journal.pone.0122656

4. Deslée G, Mal H, Dutau H, et al. Lung volume reduction coil treatment vs usual care in patients with severe emphysema: the REVOLENS randomized clinical trial. JAMA. 2016;315(2):175-184. doi:10.1001/jama.2015.17821

5. Sciurba FC, Criner GJ, Strange C, et al. Effect of endobronchial coils vs usual care on exercise tolerance in patients with severe emphysema: the RENEW randomized clinical trial. JAMA. 2016;315 (20):2178-2189. doi:10.1001/jama.2016.6261

6. Gülsen A. Effects of bronchoscopic lung volume reduction coil treatment on arterial blood gases. J Bronchology Interv Pulmonol. 2019;26 (2):90-95. doi:10.1097/LBR.0000000000000529

7. Toker Ugurlu T, Ugurlu E. Impacts of coil treatment on anxiety and depression in emphysema. Can Respir J. 2020;2020:e4270826. doi: $10.1155 / 2020 / 4270826$

8. Slebos D-J, Ten Hacken NH, Hetzel M, Herth FJF, Shah PL. Endobronchial coils for endoscopic lung volume reduction: best practice recommendations from an expert panel. Respiration. 2018;96 (1):1-11. doi:10.1159/000490193

9. Slebos D-J, Cicenia J, Sciurba FC, et al. Predictors of response to endobronchial coil therapy in patients with advanced emphysema. Chest. 2019;155(5):928-937. doi:10.1016/j.chest.2019.02.012 
10. Klooster K, Valipour A, Marquette C-H, et al. Endobronchial coil system versus standard-of-care medical management in the treatment of subjects with severe emphysema. RES. 2021;100(8):804-810.

11. Gulsen A, Sever F, Girgin P, Tamci NB, Yilmaz H. Evaluation of bronchoscopic lung volume reduction coil treatment results in patients with severe emphysema. Clin Respir J. 2017;11 (5):585-592. doi:10.1111/crj.12387

12. Turan D, Doğan D, Çörtük M, et al. Real life results of coil treatment for bronchoscopic lung volume reduction in emphysema. Tuberk Toraks. 2020;68(1):17-24. doi:10.5578/tt.69320

13. Deslée G, Leroy S, Perotin JM, et al. Two-year follow-up after endobronchial coil treatment in emphysema: results from the REVOLENS study. Eur Respir J. 2017;50(6). Available from: https://erj.ersjournals. com/content/50/6/1701740. Accessed September 30, 2021.
14. Gompelmann D, Heinhold T, Rötting M, et al. Long-term follow up after endoscopic valve therapy in patients with severe emphysema. Ther Adv Respir Dis. 2019;13:1753466619866101. doi:10.1177/ 1753466619866101

15. Garner JL, Kemp SV, Srikanthan K, et al. 5-year survival after endobronchial coil implantation: secondary analysis of the first randomised controlled trial, RESET. Respiration. 2020;99(2):154-162. doi:10.1159/000505274

16. Celli BR, Cote CG, Marin JM, et al. The body-mass index, airflow obstruction, dyspnea, and exercise capacity index in chronic obstructive pulmonary disease. $N$ Engl J Med. 2004;350(10):1005-1012. doi:10.1056/NEJMoa021322

\section{Publish your work in this journal}

The International Journal of COPD is an international, peer-reviewed journal of therapeutics and pharmacology focusing on concise rapid reporting of clinical studies and reviews in COPD. Special focus is given to the pathophysiological processes underlying the disease, intervention programs, patient focused education, and self management protocols. This journal is indexed on PubMed Central, MedLine and CAS. The manuscript management system is completely online and includes a very quick and fair peer-review system, which is all easy to use. Visit http://www.dovepress.com/testimonials.php to read real quotes from published authors. 